\title{
Anomalous Experience of Self and World: Administration of the EASE and EAWE Scales to Four Subjects with Schizophrenia
}

\author{
Jérôme Englebert ${ }^{\mathrm{a}}$ François Monville ${ }^{\mathrm{b}}$ Caroline Valentiny ${ }^{\mathrm{a}}$ \\ Françoise Mossay ${ }^{a}$ Elizabeth Pienkos ${ }^{c}$ Louis Sass $^{d}$ \\ ${ }^{a}$ Department of Psychology, University of Liège, Liège, Belgium; ${ }^{b}$ Hôpital AGORA, ISoSL, Liège, Belgium; \\ 'Department of Psychology, Clarkson University, Potsdam, NY, USA; ${ }^{\mathrm{d}}$ Department of Clinical Psychology, GSAPP, \\ Rutgers University, Piscataway, NJ, USA
}

\section{Keywords \\ Self-experience - World experience - Examination of Anomalous Self-Experience (EASE) - Examination of Anomalous World Experience (EAWE) · Schizophrenia}

\begin{abstract}
The aim of this paper was to study anomalies of self- and world experience in schizophrenia from a phenomenological perspective through the use of the Examination of Anomalous Self-Experience (EASE) and Examination of Anomalous World Experience (EAWE) interviews. Four patients with diagnoses of schizophrenia were interviewed with both the EASE and the EAWE. A qualitative analysis of these interviews was carried out on all the data; quantitative scores were also assigned, based on the frequency and intensity of the items endorsed by the subjects. In the EASE, the subjects endorsed an average frequency of $45 \%$ of all items. In the EAWE, the subjects endorsed an average frequency of $26 \%$ of all items. Furthermore, the EAWE data indicated more heterogeneous profiles of experience than the EASE data. This heterogeneity is not surprising, given that the EAWE was designed to be a more broad-based or less targeted exploration of various changes likely to be associated with the schizophrenia spectrum (but also with certain other conditions). Our data sug-
\end{abstract}

\section{KARGER}

(c) 2019 S. Karger AG, Basel

E-Mail karger@karger.com

www.karger.com/psp gest that although disturbances of world experience may always be present in schizophrenia, they may take numerous and varied forms. Because the experience of the world occurs across many different modalities, disturbances of this experience would be fundamentally less unitary, whereas the experience of the self presents a more coherent and unitary gestalt. These results show a certain overlapping between the scales while also indicating the potential value of a combined use of the two instruments. Finally, we discuss the relationship between experiential description and behavioral observation, and their potentially complementary value in exploring the first-person perspective, particularly in the case of experiences that occur at a more prereflective level.

(c) 2019 S. Karger AG, Basel

\section{Introduction}

The phenomenological approach in psychiatry focuses on experience as lived in the first person. It attempts to understand and define the structure of subjectivity of persons with various forms of psychopathology [1-3]. While recognizing the uniqueness of each individual, phenomenological psychopathology also attempts to illuminate

Jérôme Englebert

Department of Psychology, University of Liège

Place des Orateurs 2

BE-4000 Liège (Belgium)

E-Mail jerome.englebert@uliege.be 
invariants - what have been called "existentials" - both in ordinary and in abnormal forms of human existence. The focus of phenomenology is less on the contents of thought and lived experience than on distinctive aspects of the overall form of experience.

Schizophrenia is of particular interest to psychiatric phenomenology for two reasons. Firstly, it is difficult to define as a nosological entity. The phenomenological reduction, which brackets out commonsense assumptions about selfhood and the world in order to focus on experience as it is lived, may allow researchers and clinicians to isolate some essential features of schizophrenia, thereby making it possible to identify and understand its unique mode of being. Secondly, the subjects affected by schizophrenia are thought to experience a loss of natural self-evidence, that is, an experience of perplexity regarding themselves and the world and a loss of commonsense modes of perception and behavior (an experience that, interestingly enough, can at times have something in common with the intentional bracketing of the natural attitude in phenomenology [4]). Such persons may experience a near-constant form of reflexive self-awareness - an awareness that may operate in an automatic and involuntary fashion (as a popping-out of what would normally be experienced only implicitly, in the background of awareness), but that can also take on a more intentional and sometimes intellectual form of self-reflection. In this way such persons become aware of, and may even reflectively question and analyze, events, processes, or aspects of the world that are typically implicit and taken for granted, including the flow of consciousness itself.

This latter aspect is studied by contemporary authors as one of the facets of "self-disturbance" or "ipseity disorder," thought to characterize schizophrenia. The self here is conceived as the implicit organizer or center of lived experience. According to Sass and Parnas $[5,6]$, the fundamental disturbance in schizophrenia is a disruption of the basic self, which comprises three aspects: (1) hyperreflexivity, which is characterized by an exaggerated selfconsciousness, a (fundamentally nonvolitional) tendency for focal attention to be directed toward processes and phenomena that would normally be "inhabited" or experienced (tacitly) as part of oneself; (2) diminished self-affection or self-presence, which refers to a decline (passively or automatically) in the sense of existing as a subject of living and unified awareness and as the agent of one's actions; and, finally, (3) a "disturbed hold" or "grip" on the world, involving disturbances in the stability and salience of worldly objects and events.
The aim of this article was to qualitatively study anomalies of self-experience and disturbances in the adaptation to the social world and to the environment from a phenomenological standpoint by using the Examination of Anomalous Self-Experience (EASE) [7] and the Examination of Anomalous World Experience (EAWE) [8]. Two questions will be asked: (1) do these instruments make it possible to identify experiences that are specific to schizophrenia by offering a discursive and clinical framework that allows schizophrenia subjects to describe their experiences, and (2) to what degree do scores and responses on the EASE and EAWE correspond?

\section{Method}

We interviewed 4 patients, 3 males and 1 female, all diagnosed with schizophrenia according to DSM- 5 criteria (Pascale, 41 years, Michel, 36 years, Antoine, 26 years, and Thomas, 41 years; the names are changed for reasons of confidentiality). All were hospitalized in a psychiatric facility and agreed to participate in this research. The EASE and EAWE interviews were administered to each subject; each scale required, on average, five 50-min clinical interviews. Once the two scales had been administered - following the interviewing procedures recommended for the two interviews - a qualitative analysis of the reported experiences, based on an analysis of discourse, was carried out on all the data and a quantitative score was assigned to the different items based on their frequency and intensity.

\section{Examination of Anomalous Self-Experience}

The EASE allows the semi-structured exploration of a variety of anomalies of subjective experience which are considered disorders of self-awareness [7]. The scale was developed using self-descriptions provided by patients with schizophrenia and clinical descriptions from the literature of phenomenological psychiatry and classic psychopathology. This tool is intended primarily for people with schizophrenia spectrum disorders, though it is not intended to be used alone for the purposes of diagnosis (additional tools such as a clinical interview and observation are required for standard diagnostic purposes). The EASE has been used in many studies, which have highlighted the specificity of self-disorders in schizophrenia in contrast with certain other conditions $[3,9-15]^{1}$.

\footnotetext{
1 However, it should be specified that recent research [16] suggests that EASE items may be considerably less "specific" to the schizophrenia spectrum when compared with nonschizophrenic subjects having significant depersonalization/derealization symptoms rather than with the severe affective disorder patients previously used as a control or contrast group. There is some debate on the implications of this finding. It may be argued that the EASE should be interpreted purely in gestalt-oriented terms, and that higher EASE scores nevertheless identify this gestalt even when the difference is less dramatic. This may be so, but the above-mentioned findings do suggest that the depersonalization/derealization syndrome (which can be found outside the schizophrenia spectrum) is overlapping especially significantly with schizophrenia [see 5,17$]$.
} 
The EASE consists of five different domains (each comprising between 5 and 18 items, with 57 items in total): (1) "Cognition and stream of consciousness," (2) "Self-awareness and presence," (3) "Bodily experiences," (4) "Demarcation/transitivism," and (5) "Existential reorientation" [for a complete description of the instrument, see 3, 7].

\section{Examination of Anomalous World Experience}

The EAWE facilitates the semi-structured exploration of a variety of subjective anomalies of an individual's experience of the outside world, language, and other people $[8,18]$. It is intended to be used either independently or complementarily with the EASE, depending on the purpose of the interview, and can be used either in its entirety or by selecting certain areas (e.g., the domain of "Space and objects" or "Language"). Due to the intertwining of self- and world experiences, the scales have a number of overlapping items. Unlike the EASE, which was designed to capture the various manifestations of a core disturbance of ipseity or minimal selfhood [6], the EAWE's primary objective is to facilitate a wideranging exploration of anomalous experiences, in schizophrenia and beyond $[8,19]$. One possible outcome of extensive EAWE research might be to identify which specific EAWE items or subtypes, among the many, tend to be most characteristic of individuals with schizophrenia spectrum disorders in particular, bearing in mind that these individual items or subtypes might not cluster in any single EAWE domain. This, however, would be only one possible outcome; it does not define the essential purpose of the EAWE, which is broader and more exploratory in nature.

The EAWE is very new ${ }^{2}$ and this contribution is among the first research studies to use it [see also 20,21]. Our study aimed to evaluate its ability to identify and explore specific experiences within the schizophrenic spectrum. The EAWE is composed of six different domains related to anomalies of world experience (each comprising between 6 and 17 items, with a total of 75 items): (1) "Space and objects," (2) “Time and events," (3) "Other persons," (4) "Language," (5) "Atmosphere," and (6) "Existential orientation." Some items (and subtypes) are marked with an asterisk $\left(^{*}\right)$, which indicates experiences that, although present in schizophrenia, might also be expected to be fairly common in some other forms of psychosis (delusional disorder, bipolar disorder, or severe depressive disorder) [for a full description of the instrument, see 8,19 ].

\section{Results}

\section{Quantitative Data}

We first indicate for each patient the quantitative data obtained for the two scales (summarized in Table 1). Although no quantitative conclusions can be drawn with such a small sample, it may be useful to consider trends in the occurrence of items.

2 The EAWE is currently being translated into French (by the authors of this paper). For this research, we have used a translation (also completed by our team) of a beta version of the EAWE.

Anomalous Experience of Self and World
Table 1. Percentage of items represented in each area of the EASE and EAWE scales

\begin{tabular}{|c|c|c|c|c|c|c|c|c|c|c|c|c|c|}
\hline & \multicolumn{6}{|c|}{ EASE domain } & \multicolumn{7}{|c|}{ EAWE domain } \\
\hline & total & 1 & 2 & 3 & 4 & 5 & total & 1 & 2 & 3 & 4 & 5 & 6 \\
\hline Pascale & 44 & 71 & 44 & 11 & 20 & 38 & 17 & 12 & 0 & 29 & 20 & 17 & 18 \\
\hline Antoine & 32 & 29 & 39 & 22 & 20 & 38 & 14 & 18 & 0 & 21 & 0 & 18 & 18 \\
\hline Michel & 49 & 53 & 67 & 33 & 20 & 38 & 31 & 47 & 13 & 29 & 30 & 41 & 9 \\
\hline Thomas & 58 & 59 & 56 & 56 & 40 & 75 & 40 & 47 & 63 & 43 & 30 & 18 & 55 \\
\hline
\end{tabular}

The total percentages of items represented by the EASE for each subject were 58\% (Thomas), 49\% (Michel), 44\% (Pascale), and 32\% (Antoine). The average percentage across all 4 subjects was $45 \%$. Domains 1 (Cognition and stream of consciousness) and 2 (Self-awareness and presence) had the highest percentages of items endorsed.

For the EAWE, the percentages of items endorsed by each subject were 40\% (Thomas), 31\% (Michel), 17\% (Pascale), and 14\% (Antoine). The average percentage of items was lower (26\%) than on the EASE, and the profiles of the EAWE data were more heterogeneous; only EAWE domain 3 (Other persons) was prominent in all 4 subjects. Neither the lower percentage nor the heterogeneity is surprising, given the more broad-based nature of the EAWE, whose focus (as noted above) is less targeted than that of the EASE.

\section{Qualitative Data}

We will now highlight the salient features of experience identified by the EASE and EAWE analyses in each of the 4 patients, as well as various points of overlap between the two scales. By "salient" we mean those features or aspects that the patient himself, in the interview, seemed to consider especially important in his experience.

\section{Pascale}

Pascale is 39 years old and was diagnosed with schizophrenia a decade ago. She has been receiving antipsychotic medication for several years while maintaining a pronounced psychotic symptomatology, primarily related to her thoughts. She feels that her mind is transparent to others in certain situations, that her thoughts can be heard by others and her mental images viewed. Pascale describes herself as an anxious and introverted person who constantly pays conscious attention to herself, to her way of acting or behaving, without being able to engage in the world in a natural or spontaneous way. 
The anomalous experiences (regarding self and then world) that seemed especially salient for her are as follows.

\section{(a) EASE}

Perceptualization of Inner Speech or Thought (1.7). Pascale's thoughts or inner discourse acquire auditory qualities, which is related to her feeling that the people around her are likely able to hear them.

Distorted First-Person Perspective (2.2) and Hyperreflectivity; Increased Reflectivity (2.6). Pascale does not really recognize some of her thoughts as her own. She also describes a constant self-monitoring in which she feels compelled to take herself as an object of reflection, preventing her from engaging more immediately with the environment.

Loss of Common Sense (2.12). She often wonders how she should act in the presence of others, especially how and when she should laugh or smile.

Cenesthetic Experiences (3.7). Pascale reports a "sparkle of the eyes," which she explains as the physical perception that her eyes are reacting to stressful situations. This sizzle can be perceived by others, she says, and can be a hindrance in building interpersonal relationships.

\section{(b) EAWE}

Sense of Inferiority, Criticism, or Mistrust in Relation to Others* (3.4). Pascale frequently devalues and often feels less intellectually "capable" than others. This is related to difficulties of concentration and memory, which make her highly self-conscious when they occur.

Disturbance of Self-Other Demarcation (3.7). Pascale reports difficulties in establishing a clear distinction between herself and others, and a feeling of being "permeable" to others. The relevant experiences can involve her "audible" thoughts or the mental images she believes are somehow "visible" to others.

Self-Referentiality (5.14.2). Pascale feels that she is the direct cause of changes in her environment. She has thought, for example, that a patient in the hospital was discharged because of her or that people who look back at her on the street feel embarrassed by her.

Feeling of Centrality (6.10). In the past, following a mystical delirium, Pascale believed that her mission was to purify the world and help every person on Earth. Currently, she says she can sometimes feel like she is the center of everyone's attention.

It should be noted that almost all of Pascale's experiences discussed during the administration of the EAWE (some of which are mentioned above) had already been mentioned during the administration of the EASE. (This is not surprising, as the EAWE items at issue are ones for which the overlap with self-aspect also seems clear.) The EAWE did, however, allow for a more detailed exploration of these phenomena.

\section{Antoine}

Antoine is 26 years old and was diagnosed with schizophrenia 8 years ago. He responds favorably to antipsychotic medication and presents as clinically stable. He speaks of "psychotic crises" that appeared following an episode of cannabis abuse around the age of 18 years.
During these crises, he said he felt "out of the world." He describes a feeling of persecution at the time, which is no longer present. He also speaks of a "psychotic intelligence," which he defines as a focus on everything and the ability to make connections between these different things. Antoine does not feel "schizophrenic" anymore; he makes a clear distinction between the person he was in the past, a psychotic and "weak" person who had "crises," and the person he is today, someone strong and in good mental health.

\section{(a) EASE}

Hyperreflectivity; Increased Reflectivity (2.6). The "psychotic intelligence" emphasized by Antoine is linked to a tendency toward interpreting events around him as well as a "quest for meaning." In these, he uses a kind of paranoid logic, and also demonstrates a hyperconsciousness of details of his perceptual field, despite the fact that he knows that people in general do not typically engage in such reflective questioning of the events and objects they experience.

Cenesthetic Experiences (3.7). At times, Antoine feels a burning, as if his skin is being "cooked," or he can hear his heartbeat as if it were resonating.

Magical Ideas Linked to the Subject's Way of Experiencing (5.6). He thinks he perceives "signs," for example, when a particular sound is repeated; he denies the possibility that such events might be simply random and makes idiosyncratic interpretations of these "signs." He also has the occasional feeling of being able to control certain things in his environment (weather, radio, etc.).

Existential or Intellectual Change (5.7). He engages in lengthy reflections on physics, on the governing bodies of the world, as well as on psychology broadly speaking.

\section{(b) EAWE}

Abnormal Intensity or Persistence of Auditory Perceptions (1.9). Some sounds appear increased in intensity, as if a whispered sentence were spoken at regular volume; some sounds seem to be prolonged, as if the sound of a radio continued after it was turned off.

Disturbances of Other Senses* (1.13). Antoine experiences gustatory and olfactory hallucinations, sometimes having the impression of smelling or tasting cannabis without it being present.

Déjà $V u$ Experiences (5.5). At times, Antoine says he feels a sense of having already lived through what he was experiencing in the present moment, as if events were being repeated.

Rejection of Society or Convention (6.1). With respect to authority, Antoine adopts an attitude of opposition, refusing to comply with certain commonly accepted rules and laws (refusal to work, use of physical aggression despite being aware of the consequences that may result from his actions).

The EAWE made it possible to highlight two types of experience in Antoine: the disturbance of his sensory experience and his opposition to social conventions and norms (although the latter point was implicitly conveyed during the EASE interviews).

Michel

Michel is 36 years old and was diagnosed with schizophrenia a decade ago. He responds favorably to antipsy- 
chotic medication and has been presenting as clinically stable for several years. Michel is a rather anxious person, presenting with a worried look in his eyes and giving the impression of almost apologizing for existing. He speaks readily of his feelings of inferiority toward others, and of his illness, which prevents him from being able to connect with others and the world more naturally. He explains that he has lived for a long time with a feeling of persecution, which has now greatly diminished even though he continues to gravitate toward paranoid interpretations. He describes frequently feeling like he is disturbing others, as though what he has experienced in his life makes him different from others, and as if he is somehow transparent to others.

\section{(a) EASE}

Ruminations-Obsessions (1.6). Michel explains that when he has a goal to achieve (such as completing a written report for a training), he puts a lot of pressure on himself and fails to enjoy other activities until the task is completed. He then frequently feels invaded by thoughts about this goal, and these anxious ruminations prevent him from being able to relax.

Diminished Sense of Basic Self (2.1). Michel has the impression that there is some sort of gap in his experience of himself, a lacuna that others do not feel; and he sometimes feels transparent to others. Michel says he has difficulty appreciating himself, is critical of himself, and thinks that he is not doing things the right way or that he is useless, not up to the task.

Primary Self-Reference Phenomena (5.1). Michel feels that he directly causes what happens in his environment. For example, he feels responsible for the background noise in a classroom.

Existential or Intellectual Change (5.7). He explains that his interest in Buddhism appeared during a psychotic decompensation. He says that he frequently questions the foundation of life, wondering about what happens after death and about the meaning of existence.

\section{(b) EAWE}

Disturbances Involving Veridicality (Accuracy) of Visual Perceptions* (1.3). He reports visual illusions, such as arbitrarily seeing meaning in a shadow.

Disturbances Involving Veridicality (Accuracy) of Auditory Perceptions* (1.10). Michel reports auditory illusions, such as the impression that a person is pronouncing his name while pronouncing someone else's name, or else that a noise is amplified (usually in connection with social anxiety).

Problems Localizing Sounds (1.12). In connection with auditory illusions, Michel sometimes has difficulties locating where a sound comes from, including sometimes thinking that an outside noise comes from inside himself.

Anomalies of Mood or Affect (5.17). Michel describes a certain blunting of affect, which was especially present in the past but which he still feels occasionally, as well as partial anhedonia.

Concerning Michel, the main contribution of the EAWE is in its ability to highlight changes in auditory perceptions, particularly auditory illusions, which are related to a primary phenomenon of self-reference. In addition, the scale identifies Michel's feel- ings of apathy. The other experiences cited above, such as a feeling of inferiority or self-referentiality, had also been noted in the EASE interview.

\section{Thomas}

Thomas is 41 years old and was diagnosed with schizophrenia 6 years ago; it has been a relatively short time since he was stabilized clinically. Thomas is the only one of the subjects in this study to present with an almost permanent delusional background, which he has now learned to manage. He reports that he no longer experiences thoughts; instead he only hears voices, mainly that of the Holy Spirit who guides him. These voices are the first information he provides about himself: he defines himself through them, indicating the crucial role of auditory hallucinations in his identity. Thomas explains that it is Christ who lives in him and who dictates his actions or behaviors, without Thomas truly intending or being aware of them.

\section{(a) EASE}

Disturbance of Thought Initiative/Intentionality (1.11). Thomas explains that he no longer has the intellectual capacity necessary to retrieve memories, or to engage in reflective questioning and engagement with a particular subject.

Distorted First-Person Perspective (2.2). Thomas states that he does things and behaves mechanically because he is controlled by the Holy Spirit. None of his decisions, none of his acts are really his. He expresses a loss of "mineness" of experience: his thoughts, sensations, and actions seem like they do not belong to him and as if they occur automatically and mechanically. For Thomas, this feeling of diminished "mineness" appears to be pushed to an extreme, as he states he does not know who he was before this change. It also implies an experiential or phenomenological distance between self and experience, as Thomas feels that he does things "at a distance"; the self and the experience are completely dissociated, separated into two very distinct things.

Extraordinary Creative Power, Extraordinary Insight (5.4). Thomas thinks that he can "establish things for the multitude" and that he is able to see and hear things communicated to him by the Holy Spirit. In the past, he felt a sense of superiority over others, since he thought he could have a direct influence on their behavior and their lives. In addition, he also thinks he has healing gifts, allowing him to cause the pain of others to disappear.

Existential or Intellectual Change (5.7). Thomas is preoccupied with God, the Bible, and the role he has to play in the world. These preoccupations appeared 7 years ago, at the time of his first psychotic decompensation.

\section{(b) EAWE}

Disruption of Dynamic Organization of Time (2.3). Thomas' experience of time is highly idiosyncratic; time can be accelerated, slowed down, stopped, or rewound, all in response to his own will. Paradoxically, he also feels stuck in the present, as if his access to the future is blocked. 
Disturbance of Self-Other Demarcation (3.7). Thomas believes that he has unusual influence over others, that he is able to control them in order to help them to "get better" in some way. Conversely, he feels that he too is controlled by the Holy Spirit and is no longer in control of his life, as if God were in him. The boundaries between himself and others can be blurred because of a process he calls "visiting," which involves mixing his body with the people he "visits" (to heal them from their ailments).

Diminished Ontological Independence of Experienced World/ Subjectivism (5.13). Thomas adopts a solipsistic position, thinking, for example, that when his life comes to an end, the world will also stop.

Decentering of the Selfrelative to the Universe (6.11). For Thomas, there are several realities: this one, and various copies of it in which people all have a common characteristic (their holiness, their madness, etc.). He also feels that our reality may not be the right or correct one, either because there are many realities or because this reality could be a dream.

Thomas reports the highest frequency of both EAWE and EASE items of all the subjects of this study. The EAWE revealed a large number of time-related anomalies that would not have been demonstrated by administering only the EASE. It is particularly interesting to note that this subject, who presents the most significant psychotic symptomatology, also describes the highest number of anomalous world experiences (especially in the temporal dimension, which may well play a foundational role in his overall experience). It is tentatively suggested, therefore, that intense psychotic experience could involve certain changes in world experience (or a greater awareness of such changes) that would be less characteristic during phases of greater clinical stability; this hypothesis might be a topic for future research (perhaps involving detailed qualitative analysis of the experience of psychotic stabilization).

\section{Discussion}

\section{Common Items}

We will present, for each of the two scales, the items most often reported by our 4 subjects. We cannot say that in our 4 subjects any one of the general interview domains is present much more consistently than are the other domains, though EASE domain 2 (Self-awareness and presence) and EAWE domain 3 (Other persons) do seem especially prominent. This seems to be consistent with theories suggesting that the phenomenology of schizophrenia is essentially related to disturbances of both self and intersubjectivity. Despite the overall heterogeneity of the forms of anomalous experience of self or world across subjects, it is nevertheless possible to highlight certain similarities and common poles of experience.

\section{(a) EASE}

Several EASE items were present in all of the 4 subjects, namely: Thought interference (1.1); Distorted first-person perspective (2.2); Hyperreflectivity; increased reflectivity (2.6); Dissociative depersonalization (2.8); Anxiety (2.13); and Cenesthetic experiences (3.7). Note that Loss of common sense/perplexity/lack of natural evidence (2.12) is not included in this list, despite the fact that it seemed central to each subject; though explicitly formulated only by Pascale, it was nevertheless observed in a striking way during the interviews. We return to this observation below.

\section{(b) EAWE}

None of the EAWE items (or subtypes) were present in all 4 subjects. We therefore record the anomalies of world experience that were present in at least 3 of the subjects. These items, presented by 3 out of 4 subjects, are: Disturbances involving veridicality (accuracy) of visual perceptions* (1.3); Visual fragmentation (1.4); Abnormal intensity or persistence of auditory perceptions (1.9); Disturbances of other senses* (1.13); Sense of inferiority, criticism, or mistrust in relation to others* (3.4); Difficulties with the gaze (3.8); Specific changes in standard feel or meaning of words (4.3); Diminished ontological independence of experienced world/subjectivism (5.13); and Existential or intellectual change* (6.9). It is noteworthy that 4 of these 9 are asterisk items, meaning they were deemed, on theoretical/clinical grounds, to be common in the schizophrenia spectrum but not necessarily specific to it.

\section{Contributions from the EAWE versus the EASE Scale}

Specificity of the Phenomena Described by the EAWE

As expected, the subjects in our study reported fewer experiences described by the EAWE than those described by the EASE. As a general rule, EASE items appeared to be more easily recognized by patients and to represent experiences that were somewhat easier for them to differentiate or describe. Many of the experiences addressed by the EASE have a global quality (e.g., Diminished sense of basic self [2.1]). Some EAWE items also aim at rather global experiences (e.g. Disruption of dynamic organization of time [2.3] or Decentering of the self relative to the universe [6.11]), but there are also many items in the EAWE that target more specific features of lived experience (e.g. Abnormal intensity or persistence of visual perceptions [1.1], Problems localizing sounds [1.12], or Déjà vu experiences [5.5]). As noted, some frequently identified EAWE items overlapped with EASE items.

It is important to note that these results do not indicate that in schizophrenia abnormalities of self-experience are necessarily more central or more characteristic than are those of world experience - as noted, the EAWE is a more broad-based and exploratory instrument, and much 
more research would be needed to make such a determination. On the other hand, it seems possible to hypothesize that anomalous world experiences (EAWE) might well take diverse forms that are more specific to each individual subject, whereas the experience of the self might represent a more coherent or unitary gestalt whose anomalies are, perhaps, more easily identifiable, at least in schizophrenia. Metaphorically speaking, we might suggest that the experiences of the self as described by the EASE are based on a more centripetal logic, whereas the experiences of the world described by the EAWE are part of a rather centrifugal logic, fanning out across more disparate domains of experience. It may turn out that the EAWE is especially useful, within the schizophrenia domain, for clarifying the forms of variability that may occur within what is widely recognized to be a somewhat heterogeneous syndrome (it should be borne in mind, however, that findings regarding the prevalence of items are themselves dependent on how broadly or narrowly these items are defined). These suggestions are, of course, of a speculative nature and deserve to be examined in future research.

Inter- and Intra-Scale Item Overlap

As stated in the EAWE, there is some overlap between the EASE and the EAWE: some EASE items are related rather directly to the "lived world" (as opposed to primarily targeting self-experience - insofar as these realms can be distinguished), and these issues are also queried in the EAWE. In addition, there are parallels between certain items (or items and a domain) of the two scales, although they do not describe strictly identical experiences. For example, the item Disturbance of time experience (1.14) in the EASE may concern various phenomena. We can assume that a subject who does not describe experiences related to EASE item 1.14 will not endorse or describe the more specific items in the "Time and events" domain (domain 2) of the EAWE. This was indeed the trend observed in our subjects: Pascale, Antoine, and Michel did not describe any disturbances in time experience (item 1.14) during the EASE interview, and they also did not describe any disturbances in items of EAWE domain 2.

On the other hand, domain 2 of the EAWE did prove very useful when EASE item 1.14 was present, i.e., with Thomas, by eliciting many additional details on the disturbances of his experience of time. An exploration of such aspects could be highly significant, e.g., in light of the suggestion that disordered temporality - which may be especially difficult for subjects to identify or report might nevertheless constitute the "trouble générateur" or

Anomalous Experience of Self and World core of schizophrenia, or at least of some types of schizophrenia [22].

We were also able to establish a link between the EASE's Loss of common sense/perplexity/lack of natural evidence (2.12) item and the EAWE's "Other persons" domain (domain 3), as the latter appeared to be directly underpinned by a loss of natural evidence. For example, when Pascale expressed a Sense of inferiority, criticism, or mistrust in relation to others* (3.4), or when Pascale and Thomas evoked a Disturbance of self-other demarcation (3.7), it is reasonable to associate these with an underlying experience of loss of natural evidence of social dynamics and its conventions. This observation suggests that the interpersonal dimension in psychotic experience is underpinned by a disturbing experience of loss of natural evidence and common sense.

Finally, we note the presence of some expected overlap between items of the EAWE scale. For example, both EAWE domain 1 and EAWE domain 5 - namely, "Space and objects" and "Atmosphere" - contain anomalous experiences of objects. In particular, it is not surprising that "Atmosphere," which by definition is the most "all-encompassing" domain, colors many other items, including those related to spatiality and the perception of objects.

\section{Joint Use}

Our experience in this study leads us to recommend the value of a joint and complementary interview using both the EASE and the EAWE, for this offers the richest insight into the experience of the interviewed subject. Indeed, it may be appropriate to group together certain analogous experiences appearing in both scales and to streamline the process by avoiding repetitions. Obviously, such a method would require an excellent command of both scales on the interviewer's part, as well as more preparatory work on the links between the two scales.

\section{First-Person Narrative and Observation}

As they are focused on the first-person perspective, the EASE and EAWE are scales based exclusively on the subject's description of his or her experience. The scoring and interpretation of items are primarily based on this self-description. Although this more verbal, often narrative dimension plays a fundamental role in understanding the structure and process of consciousness in the subject, it is not the only source of information about the ways a person comes into contact with his/her environment. The nonverbal dimension generally enriches any clinical approach and provides nuances to the verbal dimension; also, the verbal dimension (a subject's use of 
language) can be assessed from an external as well as from an internal, experiential standpoint.

For this purpose, the AMDP Rating System (Manual for Assessment and Documentation of Psychopathology in Psychiatry) [23] should be considered. This tool covers a vast range of psychopathological symptoms and signs (126 items) and aims to provide an overview of the patient's present clinical status. Like the EASE and EAWE, the AMDP is based on semi-structured interviews, but its rating system combines the first-person perspective with (third-person) observation in a fruitful way. Indeed, it offers two types of symptom: those experienced by the patient and those observed by the examiner. For example, item 15 ("Inhibited thinking") is accompanied by the letter "S," meaning that this sign must be evaluated according to the person's subjective experience. Item 16 ("Retarded thinking") is followed by an "O," indicating that the evaluation is according to the appraiser's observation. Some criteria include both indications, which can be shown as "Os" or "So" meaning the prevalence of one over the other in the evaluation of the item. The addition of an "observed" dimension to the EASE and EAWE scales (which would be applicable to some subset of EASE and EAWE items) could enhance the overall understanding of the person, providing insight derived not only from the experiential narrative of the patients but also from the way that the patients are experienced in their social or behavioral comportment. We suggest that one of the future challenges faced by phenomenological psychopathology is to integrate clinical (ethological) observation into studies focused on the first-person perspective [24, 25].

If we focus on the analysis of our 4 subjects, we note that the item Loss of common sense/perplexity/lack of natural evidence (2.12) is particularly suitable for this reflection. Our analyses, in agreement with the literature [2, 4], allowed us to emphasize the central place occupied by this experience in the life of the subjects, not because of their explicit descriptions of it, but through clinical observation. In fact, apart from Pascale, none of the subjects described any difficulties related to common sense - even though these difficulties were unquestionably present. For example, in Antoine, they are evident in the form and coherence of his speech and in the way he speaks with his interlocutor - in other words, in his relative lack of relational attunement to others when speaking with them. With Michel, the loss of common sense is also apparent in the way he relates to others and communicates, particularly in his failure to "decode" the nonverbal expressions of his interlocutor. As for Thomas, everything indicates that he lives according to another "meaning" that is different from what is taken for granted in the conventional world (arising from the feeling that the Holy Spirit lives in him and dictates his actions), although he himself specifies that he can take into consideration the "common sense" of most people.

However, it is vitally important not to mix the "experienced" and the "observed" in the rating of scales, which might then tend towards a third-person perspective that is excluded from the focus of the EASE and the EAWE. In this sense, the "observed" dimension should not be allowed to override the "experienced" dimension, although such observations can certainly prompt the interviewer to inquire about experiences perhaps associated with the observed behaviors.

These observations correspond to previous discussions regarding the use of these scales [3, 21, 26-28], which suggest that such difficulties arise from the fact that the experiences in question are often quite difficult to articulate, and that many of them may not have been translated into words prior to the interview. (Indeed, many clinicians and researchers may not even be familiar with them before encountering the EASE or EAWE.) As Parnas et al. note, "[o]ne reason for this is that many of these experiences possess a prereflective quality. They are not explicit in the focus of thematic attention but constitute more the overall background of awareness" [7, p. 237]. The verbal expression of these nearly ineffable experiences thus requires a certain capacity for using language and articulating discourse around one's own experience. In her 2014 study of the anomalies of world experience in schizophrenia, Pienkos observes a gestalt underlying schizophrenia that she calls "Unmooring of the World" $[21,29]$, involving the loss of "anchoring" to common sense. The author states that it is possible that this "unmooring" was present in the subjects of her study in the form of their response and not in the content thereof. She explains this phenomenon as follows: "Without an implicit, common-sense awareness of what counts as typical experience and what might be unusual or strange, a research subject may be unable to catalogue or speak about particularly unusual experiences" [29, p. 31]. This supports our hypothesis that experiences that are prereflective by nature will be more difficult to identify and articulate. In addition, it might allow us to identify the "moments of experience" that, by their strangeness, lie outside of common sense. Some of the more subtle EAWE items (such as Heightened intensity, aliveness, or reality of others* [3.11] or Anomalies of mood or affect [5.17]) may well be difficult to recognize or to specify, yet may provide an opening into consideration of experiences that, though important, may verge on ineffability. 


\section{Conclusion}

The EASE and the EAWE have proved to be useful in exploring anomalous experiences of the self and the world. The interviews we conducted using these instruments seem to highlight a trend of heterogeneity inherent in schizophrenia, as well as the existence of distinct "poles" of experience that are common or shared in the disorder.

A qualitative analysis of and reflection on the responses to the two scales highlights the specificities of the phenomena described by the EASE and EAWE (e.g., generally more specific in the former and more global in the latter). Consideration of the overlapping features and uses of the scales suggests the value of using them in combination.

Finally, we discussed the relationship between experiential description and observation in the context of the first-person perspective. From this standpoint, we have pointed out that, because of the prereflective nature of certain anomalies of self-experience and of the world, it is possible that only persons with schizophrenia who have high levels of introspection and verbal skill may be able to articulate certain anomalies that might nevertheless be present on a broader scale.

Future research might involve larger-scale, quantitative studies combining the two scales. If participants regularly endorse specific items or groups of items in the EASE along with specific items or groups of items in the
EAWE, this would help clarify the nature of the relationship between self- and world experience. Also, such research might possibly help to identify specific "types" of schizophrenia, namely, groups tending to identify certain groupings of EASE and EAWE items; for instance, some groups might tend to endorse items related to depersonalization and derealization, while others might more often endorse items related to disturbances in common sense (or some other grouping of experience).

In addition, it would be useful to investigate the relationship between a clinician's or other observer's perspective and that of the patient's first-person reports - for example, by systematically evaluating the correlation of certain items (such as loss of common sense) as rated by the patient versus the correlation of the same items as rated by the clinician.

\section{Statement of Ethics}

The patients gave their informed consent. This study was endorsed by the ethics committees of the hospital and the University of Liège.

\section{Disclosure Statement}

The authors declare no conflicts of interest.

\section{References}

1 Minkowski E. La schizophrénie. Paris: Petite Bibliothèque Payot; 1927.

2 Stanghellini G. Disembodied spirits and deanimated bodies: the psychopathology of common sense. Oxford: Oxford University Press; 2004.

3 Englebert J, Valentiny C. Schizophrénie, conscience de soi, intersubjectivité: Essai de psychopathologie phénoménologique en première personne. Bruxelles: De Boeck; 2017.

4 Blankenburg W. Der Verlust der natürlichen Selbstverständlichkeit: Ein Beitrag zur Psychopathologie symptomarmer Schizophrenien. Stuttgart: Enke; 1971.

5 Sass LA. Self-disturbance and schizophrenia: structure, specificity, pathogenesis (Current issues, New directions). Schizophr Res. 2014 Jan;152(1):5-11.

6 Sass LA, Parnas J. Schizophrenia, consciousness, and the self. Schizophr Bull. 2003;29(3): 427-44.

7 Parnas J, Møller P, Kircher T, Thalbitzer J, Jansson L, Handest P, et al. EASE: Examination of Anomalous Self-Experience. Psychopathology. 2005 Sep-Oct;38(5):236-58.
8 Sass L, Pienkos E, Skodlar B, Stanghellini G, Fuchs T, Parnas J, et al. EAWE: Examination of Anomalous World Experience. Psychopathology. 2017;50(1):10-54.

9 Englebert J, Stanghellini G, Valentiny C, Follet V, Fuchs T, Sass L. Hyper-réflexivité et perspective en première personne: un apport décisif de la psychopathologie phénoménologique contemporaine à la compréhension de la schizophrénie. Evol Psychiatr (Paris). 2018;83(1):77-85.

10 Haug E, Lien L, Raballo A, Bratlien U, Øie M, Andreassen OA, et al. Selective aggregation of self-disorders in first-treatment DSM-IV schizophrenia spectrum disorders. J Nerv Ment Dis. 2012 Jul;200(7):632-6.

11 Nordgaard J, Parnas J. Self-disorders and the schizophrenia spectrum: a study of 100 first hospital admissions. Schizophr Bull. 2014 Nov;40(6):1300-7.

12 Parnas J, Handest P. Phenomenology of anomalous self-experience in early schizophrenia. Compr Psychiatry. 2003 Mar-Apr; 44(2):121-34.

13 Parnas J, Henriksen MG. Disordered self in the schizophrenia spectrum: a clinical and re- search perspective. Harv Rev Psychiatry. 2014 Sep-Oct;22(5):251-65.

14 Raballo A, Parnas J. Examination of anomalous self-experience: initial study of the structure of self-disorders in schizophrenia spectrum. J Nerv Ment Dis. 2012 Jul;200(7):577-83.

15 Sass L, Pienkos E, Nelson B, Medford N. Anomalous self-experience in depersonalization and schizophrenia: a comparative investigation. Conscious Cogn. 2013 Jun;22(2):430-41.

16 Sass L, Borda JP, Madeira L, Pienkos E, Nelson B. Varieties of self disorder: a bio-phenosocial model of schizophrenia. Schizophr Bull. 2018 Jun;44(4):720-7.

17 Parnas J. A disappearing heritage: the clinical core of schizophrenia. Schizophr Bull. 2011 Nov;37(6):1121-30.

18 Madeira L, Filipe T, Cavaco T, Pienkos E, Figueira ML. The loss of nosological validity: why and how should we consider disturbances of subjective world experience? Psicopatologia Fenomenológica Contemporânea. 2018;7:29-46.

19 Sass L, Pienkos E, Fuchs T. Other worlds: introduction to the special issue on the EAWE: Examination of Anomalous World Experience. Psychopathology. 2017;50(1):5-9. 
20 Conerty J, Skodlar B, Pienkos E, Zadravek T, Byrom G, Sass L. Examination of Anomalous World Experience: a report on reliability. Psychopathology. 2017;50(1):55-9.

21 Pienkos E, Sass L, Silverstein S. The phenomenology of anomalous world experience in schizophrenia: a qualitative study. J Phenomenol Psychol. 2017;48(2):188-213.

22 Fuchs T. Temporality and psychopathology. Phenomenol Cogn Sci. 2013;12(1):75-104.

23 Broome M, Bottlender R, Rösler M, Stieglitz RD. The AMDP System: Manual for Assessment and Documentation of Psychopathology in Psychiatry. 9th ed, revised. Göttingen: Hogrefe; 2017.
24 Pienkos E, Messas G. Preface to the EAWE Portuguese version: a case for a new era of phenomenological psychopathology in psychiatry and clinical psychology. Psicopatologia Fenomenológica Contemporânea. 2018; 7(2):1-9.

25 Englebert J. Psychopathologie de l'homme en situation. Paris: Hermann; 2013.

26 Nordgaard J, Parnas J. A semi structured, phenomenologically-oriented psychiatric interview: descriptive congruence in assessing anomalous subjective experience and mental status. Clin Neuropsychiatry. 2012;9(3):1238 .
27 Nordgaard J, Revsbech R, Sæbye D, Parnas J. Assessing the diagnostic validity of a structured psychiatric interview in a first-admission hospital sample. World Psychiatry. 2012 Oct;11(3):181-5.

28 Pienkos E, Sass L. Schizophrenia, language, and the phenomenological interview. Psicopatologia Fenomenológica Contemporânea. 2018;7(2):10-28.

29 Pienkos E. The unmooring of the world: a qualitative investigation of anomalous world experiences in schizophrenia [doctoral dissertation]. Piscataway, NJ: Graduate School of Applied and Professional Psychology, Rutgers University-New Brunswick; 2014. 